\title{
Nurse plants, tree saplings and grazing pressure: changes in facilitation along a biotic environmental gradient
}

\author{
Christian Smit • Charlotte Vandenberghe • \\ Jan den Ouden · Heinz Müller-Schärer
}

Received: 16 January 2006 / Accepted: 12 December 2006 / Published online: 6 February 2007

(C) Springer-Verlag 2007

\begin{abstract}
Current conceptual models predict that an increase in stress shifts interactions between plants from competitive to facilitative; hence, facilitation is expected to gain in ecological importance with increasing stress. Little is known about how facilitative interactions between plants change with increasing biotic stress, such as that incurred by consumer pressure or herbivory (i.e. disturbance sensu Grime). In grazed ecosystems, the presence of unpalatable plants is reported to protect tree saplings against cattle grazing and enhance tree establishment. In accordance with current conceptual facilitation-stress models, we hypothesised a positive relationship
\end{abstract}

Communicated by Christian Körner.

C. Smit $\cdot$ H. Müller-Schärer

Department of Biology, Unit of Ecology and Evolution,

University of Fribourg, Chemin du Musée 10,

1700 Fribourg, Switzerland

C. Vandenberghe

Swiss Federal Research Institute WSL,

CP 96, 1015 Lausanne, Switzerland

\section{J. den Ouden}

Centre for Ecosystem Studies, Forest Ecology

and Forest Management Group, Wageningen University,

P.O. Box 47, 6700 AA Wageningen, The Netherlands

\section{Smit $(\bowtie)$}

Community and Conservation Ecology group,

Centre for Ecological and Evolutionary studies,

University of Groningen, P.O. Box 14,

9750 AA Haren, The Netherlands

e-mail: smitchr@gmail.com; c.smit@rug.nl between facilitation and grazing pressure. We tested this hypothesis in a field experiment in which tree saplings of four different species (deciduous Fagus sylvatica, Acer pseudoplatanus and coniferous Abies alba, Picea abies) were planted either inside or outside of the canopy of the spiny nurse shrub Rosa rubiginosa in enclosures differing in grazing pressure (low and high) and in exclosures. During one grazing season we followed the survival of the different tree saplings and the level of browsing on these; we also estimated browsing damage to the nurse shrubs. Shrub damage was highest at the higher grazing pressure. Correspondingly, browsing increased and survival decreased in saplings located inside the canopy of the shrubs at the high grazing pressure compared to the low grazing pressure. Saplings of both deciduous species showed a higher survival than the evergreens, while sapling browsing did not differ between species. The relative facilitation of sapling browsing and sapling survival - i.e. the difference between saplings inside and outside the shrub canopy - decreased at high grazing pressure as the facilitative species became less protective. Interestingly, these findings do not agree with current conceptual facilitationstress models predicting increasing facilitation with abiotic stress. We used our results to design a conceptual model of facilitation along a biotic environmental gradient. Empirical studies are needed to test the applicability of this model. In conclusion, we suggest that current conceptual facilitation models should at least consider the possibility of decreasing facilitation at high levels of stress.

Keywords Cattle grazing $\cdot$ Facilitation theory · Herbivory $\cdot$ Nurse effects · Unpalatable plants 


\section{Introduction}

Since the early 1990s there has been an ongoing debate on the relative importance of positive interactions between plants in terms of ecosystem functioning. Positive interactions (facilitation) could be at least as important in shaping systems as negative interactions (competition), although the latter has received far more attention in ecological research (Kareiva and Bertness 1997). Facilitation has not been included in modern ecological theories (Bruno et al. 2003), despite numerous studies on the topic. Positive interactions between plants have been particularly well demonstrated in stressful environments, such as deserts (Flores and Jurado 2003; Tewksbury and Lloyd 2001; Tirado and Pugnaire 2003), dunes (Franks 2003; Shumway 2000), salt marshes (Bertness and Ewanchuk 2002), Mediterranean mountains (Gomez-Aparicio et al. 2004) and alpine steppes (Callaway et al. 2002; Choler et al. 2001). In these ecosystems plants tend to cluster together, as they profit from the presence of the other, often larger, plant (called a nurse plant). These interactions between plants are expected to shift from competitive to facilitative along a gradient of increasing stress (sensu Grime 1977): neighbouring plants may experience net competitive effects when resources (water, nutrients, light) are available, but a net facilitative effect when these are limited (e.g. Bertness and Callaway 1994; Callaway et al. 2002; Callaway and Walker 1997; Holmgren et al. 1997). Consequently, facilitation is believed to become more important with increasing stress, but empirical evidence for this hypothesis is scarce. More recently, the predictions of current models have been brought into question (Maestre et al. 2005); in addition, most of these studies focussed on plant-plant interactions with increasing abiotic stress (e.g. drought, salinity, temperature). As such, very little is known about how these interactions change with increasing biotic stress incurred by consumer pressure or herbivory (i.e. disturbance sensu Grime 1977).

Recent studies show that establishment of woody species in grazed systems can be facilitated by nurse plants in the form of physically (thorns) or chemically (toxins) defensive species that protect tree saplings against large herbivores (Bakker et al. 2004; Rousset and Lepart 2000; Smit et al. 2005, 2006). This process is also known as associational avoidance, associational resistance or defence guilds (Atstatt and Odowd 1976; Milchunas and Noy-Meir 2002). It is assumed that grazing pressure is a major driving force behind this biotic facilitative process (Bokdam 2003), but again empirical evidence is scarce. In accordance with current conceptual models on facilitation and stress, one should expect that facilitation becomes more important with increasing grazing pressure - i.e. that survival of the tree sapling becomes more dependent on nurse shrubs as the grazing pressure increases. Alternatively, increased grazing pressure reduces the selectivity of herbivores as the availability of preferred food declines and, consequently, less preferred (unpalatable) plant species are consumed more frequently (Crawley 1983). In this second hypothesis, nurse plants may lose their protective role for their protégés at a high grazing pressure. Thus, in contrast with the current conceptual facilitation-stress models, one could also expect that the relative importance of facilitation decreases with increased grazing pressure, as the effectiveness of the protective plant declines.

Tree species vary in their resistance against, and attractiveness to herbivores (Bergman et al. 2005). Some species, mostly the deciduous ones, have good regrowth capacities to compensate for the loss of tissue due to browsing (Hester et al. 2004; Krause and Raffa 1996), while others prevent herbivory physically (thorns) or by means of unpalatable or less-digestible substances. The logical expectation is, therefore, that tree species should vary in terms of their dependence on nurse plants for establishment in grazed ecosystems: tree species with a low herbivore resistance would be expected to be more dependent on "nurse" plants for protection against herbivores than more grazing-resistant species.

We simulated the process of associational resistance by planting saplings of four tree species, Abies alba Miller, Picea abies (L.) (both evergreen coniferous), Acer pseudoplatanus L. and Fagus sylvatica L., Karst (both deciduous broadleaved), both under and outside the canopy of the nurse shrub Rosa rubiginosa L. in pastures with variable grazing pressures. All species co-occur naturally in the wood pastures of the Swiss Jura Mountains. The main aim of this study was to investigate how a facilitative relationship between nurse plants and tree saplings would change with increasing grazing pressure. In addition, we used the data of this experiment to develop a conceptual model of facilitation with increasing biotic stress (grazing pressure).

\section{Methods}

Study area

In 2004 we conducted a field experiment in "la Petite Ronde" $\left(6^{\circ} 27^{\prime} 26^{\prime \prime}\right.$ E, $\left.46^{\circ} 56^{\prime} 22^{\prime \prime} \mathrm{N}\right)$, a study area of 
59.2 ha situated at $1126 \mathrm{~m}$ a.s.l. near Les Verrières in the Swiss Jura Mountains. The climate is generally continental, with prevailing south-western winds, a mean precipitation of $1607( \pm 548) \mathrm{mm}$ and a mean July temperature of $14.6( \pm 1.7)^{\circ} \mathrm{C}$ (mean $\pm \mathrm{SD}$ over the period 1994-2003). The principal soil parent material is Jurassic limestone, with partly hydromorphic, acidic brown soils. The soil $\mathrm{pH}$ of the top layer ranges from 5.3 to 5.9. No fertilisers have been applied since 1986 . Vegetation is dominated by grasses (76\%), principally Festuca rubra L. and Agrostis tenuis Sibth. The mean productivity (aboveground dry matter) of the site for 2004 was $389.4 \mathrm{~g} / \mathrm{m}^{2}$. The area consists of several parks grazed by cattle according to a rotation grazing system. Different grazing pressures are achieved by varying the size of the parks, while maintaining a stable herd size of twenty-four 2-year-old heifers.

\section{Experimental design}

We selected three sites, each containing a medium(3.5-4.1 ha) and a large- (6.9-8.2 ha) sized park, resulting in a total of six parks (Table 1 ). We then fenced out an exclosure of $10 \times 60 \mathrm{~m}$ in each park. Grazing started around the middle of May and ended in early October. During the grazing season, each park was grazed for four separate periods (rotations) at either a low or a high grazing pressure, respectively: 83.6-106.1 (low) and 181.7-204.1 (high) livestock unit-days per hectare (1 livestock unit $=600 \mathrm{~kg}$ ).

In April 2004, we selected five blocks $(10 \times 10 \mathrm{~m})$ per park. Per block we planted four multi-stemmed Rosa rubiginosa (obtained from a local nursery) as nurse shrubs (approx.1.5 $\mathrm{m}$ in height) at a minimum distance of $8 \mathrm{~m}$ from each other. Rosa rubiginosa occurs naturally in the study area and has a strong natural defence against large herbivores in the form of many strong thorns. After 4 weeks, we planted tree saplings (between 10 and $20 \mathrm{~cm}$ ) of the following four tree species: Picea abies, Abies alba, Fagus sylvatica and Acer pseudoplatanus. We randomly assigned one tree species per shrub, with each block containing all four species. Eight tree saplings were transplanted in the proximity of each shrub: four directly inside the canopy ( $<10 \mathrm{~cm}$ from the stem) and four outside the canopy (1.5 $\mathrm{m}$ from the stem), all according to cardinal directions (n, e, s, w) relative to the shrub. We similarly transplanted shrubs and tree saplings in the six exclosures (five blocks each), leading to a total of three $($ sites $) \times$ two (grazing pressure $) \times$ two (grazedexclosure $) \times$ five $($ blocks $) \times$ eight $($ saplings $/$ shrub $) \times$ four $($ species $)=1920$ tree saplings.

\section{Measurements}

Before and after each of the four grazing rotations, we measured the vegetation height around all saplings outside the canopy of the nurse shrubs. We used a platform $(30 \times 30 \mathrm{~cm})$ herbometer (l'herbometre; ITCF and Arvalis, Paris, France), which was lowered down a vertical measuring rod onto the plant canopy. Vegetation height was directly stored in a data logger. The accumulated difference in vegetation height per block before and after each grazing rotation was used as an indirect measure of grazing intensity.

Browsing damage of the shrubs was estimated visually by calculating the percentage of browsed shoots in the grazed blocks after the last rotation period. A damage index (0-5) was used for this calculation in which 0 indicates $0 \%$ browsed shoots, 1 indicates $<5 \%, 2$ indicates $5-25 \%, 3$ indicates $25-75 \%, 4$ indicates $75-95 \%$ and 5 indicates $>95 \%$. Damage scores were converted to percentage median values for subsequent statistical analyses.

The initial height and diameter of all tree saplings were measured just before the cattle arrived in the field. After each grazing rotation period, we recorded the following parameters for each tree sapling: presence versus absence, browsed or not-browsed, maximal height (from ground up to the highest green needle, top or leaf) and survival. Saplings without a living stem (orange or brownish colour under bark) as well as saplings that were removed by the cattle were recorded as dead.
Table 1 Characteristics and pasturing conditions of the three sites for 2004

a Calculated as (number of LU $\times$ number of grazing days)/total grazed area, where $1 \mathrm{LU}=1$ livestock unit $(600 \mathrm{~kg})$

\begin{tabular}{|c|c|c|c|c|c|c|}
\hline \multirow{2}{*}{$\begin{array}{l}\text { Site } \\
\text { Grazing } \\
\text { pressure: }\end{array}$} & \multicolumn{2}{|l|}{1} & \multicolumn{2}{|l|}{2} & \multicolumn{2}{|l|}{3} \\
\hline & Low & High & Low & High & Low & High \\
\hline Size (ha) & 7.12 & 3.56 & 6.93 & 3.46 & 8.22 & 4.11 \\
\hline Aspect & SE & SE & $\mathrm{SE}$ & SE & WNW & WNW \\
\hline Rotation 1 & $13 / 5-23 / 5$ & $19 / 5-24 / 5$ & $23 / 5-1 / 6$ & $24 / 5-31 / 5$ & $1 / 6-14 / 6$ & $31 / 5-14 / 6$ \\
\hline Rotation 2 & $14 / 6-28 / 6$ & $14 / 6-28 / 6$ & $28 / 6-8 / 7$ & $28 / 6-8 / 7$ & $8 / 7-25 / 7$ & $8 / 7-25 / 7$ \\
\hline Rotation 3 & $25 / 7-7 / 8$ & 25/7-7/8 & 7/8-19/8 & 7/8-19/8 & $19 / 8-1 / 9$ & 19/8-1/9 \\
\hline Rotation 4 & $1 / 9-11 / 9$ & $1 / 9-11 / 9$ & $11 / 9-21 / 9$ & $11 / 9-21 / 9$ & 21/9-1/10 & $21 / 9-1 / 10$ \\
\hline LU-days/ha ${ }^{\mathrm{a}}$ & 106.1 & 189.7 & 94.9 & 181.7 & 83.6 & 204.1 \\
\hline
\end{tabular}


Data analyses

All statistical analyses were carried out on the final data (accumulated after four grazing rotations) collected from the grazed blocks. Exclosure data were used as control data on causes of sapling grazing and sapling mortality other than through cattle; both were close to zero and therefore not considered for further statistical analysis.

To verify the differences between the low- and highgrazing pressure treatments, we compared grazing intensity at the block level between treatments using one-way ANOVA. Differences in mean shrub damage between the two grazing pressures, with blocks as replication units, were tested with a one-way ANOVA $(n=30)$. The response was log-transformed to improve the homogeneity of error variances.

We defined sapling browsing and sapling survival as the fractions of saplings browsed and surviving, respectively, in each block, separately for each species, both under and outside the canopy of the shrubs. As response variable for the analyses, we took these sapling browsing and sapling survival values and averaged them over the five blocks per grazing pressure treatment (to avoid pseudo-replication), leading to 48 values. We used ANOVA, SS type III, to test for effects of site (three), grazing pressure (two), species (four), position (two, inside or outside ofthe canopy) and interactions, all treated as fixed factors. Posteriori contrasts were tested using Tukey HSD tests.

Relative facilitation for sapling browsing and sapling survival was calculated for each species per block as follows: sapling browsing inside the shrub canopy minus sapling browsing outside the shrub canopy, leading to four values per block (one for each species). Again, blocks were treated as replication units within sites. We used ANOVA to test for effects of site (three), grazing pressure (two), species (four) and interaction of grazing pressure by species on relative facilitation (of both sapling survival and sapling browsing). Further, we plotted these two response variables (relative facilitation of sapling browsing and sapling survival) against grazing pressure, resulting in a relative facilitation-grazing pressure model.

\section{Results}

Grazing intensity at block level

Grazing intensities at the block level were significantly different between the low- and the high-grazing pressure treatments $\left(F_{1,28}=7.126, P=0.013\right)$. After four grazing rotations the accumulated difference in vegetation height was $56.7 \pm 6.4$ and $90.1 \pm 10.7 \mathrm{~mm}$ (mean \pm $1 \mathrm{SE})$, respectively. Hence, the difference in grazing pressure is clearly reflected by our grazing intensity estimate at the block level.

\section{Shrub damage}

All shrubs in the grazed areas $(n=120)$ showed browsing damage by cattle, but damage levels of 4 and 5 (75-95 and $>95 \%$, respectively) were only observed at the high grazing pressure. Percentage shrub damage was $8.3 \pm 1.7$ and $37.1 \pm 10.0$ (mean $\pm 1 \mathrm{SE}$ ) for the low and high grazing pressure, respectively, and was significantly different at $P<0.05$ (one-way ANOVA, $\left.F_{1,4}=19.05\right)$.

Sapling height

At the end of the grazing season only those saplings of the low-grazing pressure treatments inside the canopy of the shrubs showed a substantial increase in height (Table 2). Those saplings located outside the canopy of the shrubs and those subjected to the high-grazing pressure treatment (saplings both inside and outside the canopy of the shrubs) were either smaller or showed no difference from their size at the start of the experiment.

Sapling browsing and survival

As expected, no sapling browsing occurred in the exclosures; sapling survival was also very high in the exclosures $-95 \%$ (26 dead) and 98\% (12 dead) survival inside and outside the canopy of the shrubs, respectively. Exclosure data were not considered for further analyses.

In the grazed areas, sapling browsing occurred during each grazing rotation period, with $42.1-84.6 \%$ of the saplings having been browsed by the end of the grazing season (Fig. 1a). Sapling survival decreased gradually until the end of the season, but was generally high at $61.3-81.3 \%$ (Fig. 1b).

ANOVA on sapling browsing revealed significant effects of grazing pressure, position and their interaction, but not of species (Table 3). Sapling browsing was significantly higher outside than inside the shrub canopy (Fig. 1a). Browsing on saplings outside the shrub canopy did not differ significantly between grazing pressures, browsing on saplings inside the shrub canopy was significantly lower at the low grazing pressure (Tukey HSD test). In addition, grazing pressure, species, position and species $\times$ grazing pressure significantly 

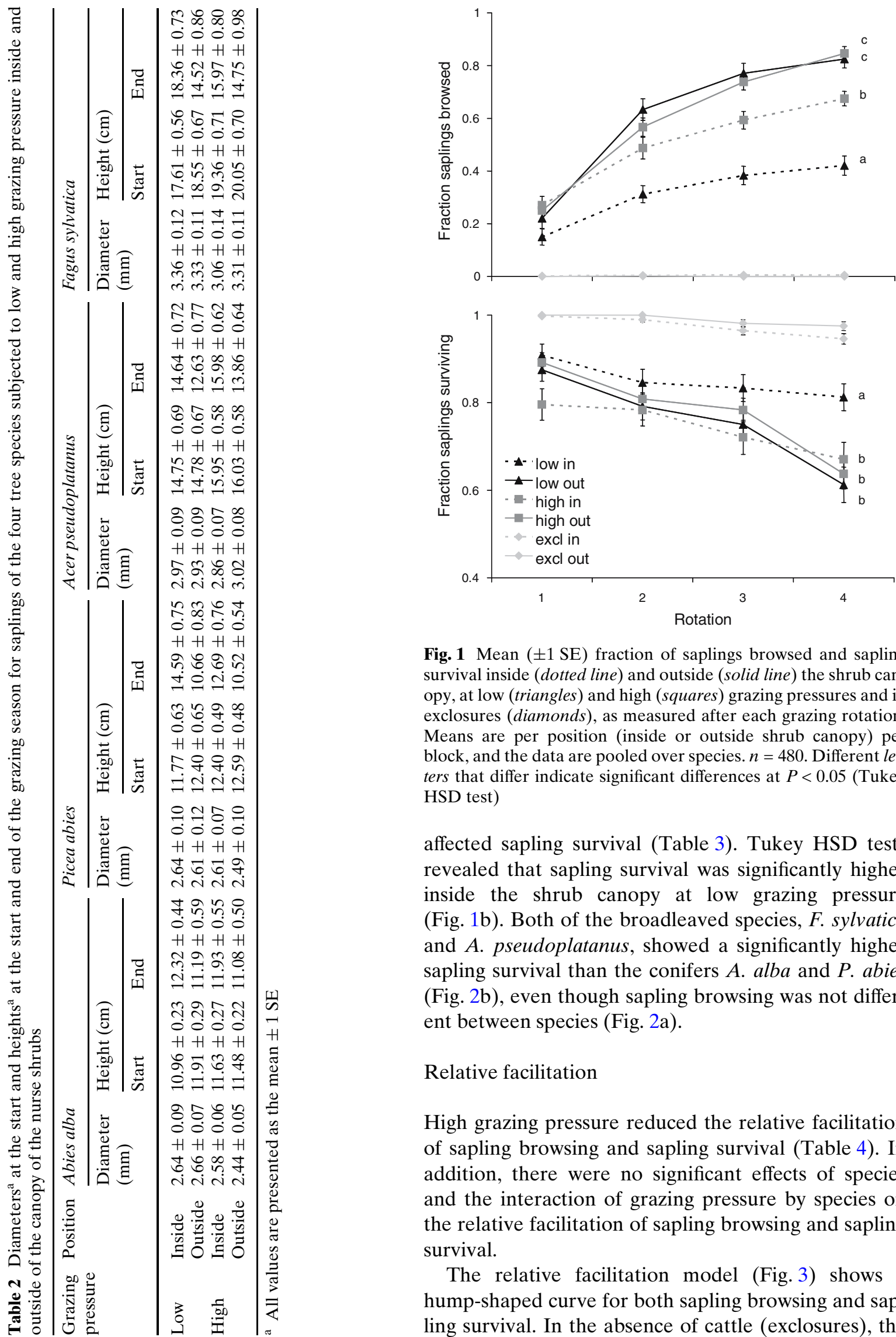

Fig. 1 Mean $( \pm 1 \mathrm{SE})$ fraction of saplings browsed and sapling survival inside (dotted line) and outside (solid line) the shrub canopy, at low (triangles) and high (squares) grazing pressures and in exclosures (diamonds), as measured after each grazing rotation. Means are per position (inside or outside shrub canopy) per block, and the data are pooled over species. $n=480$. Different letters that differ indicate significant differences at $P<0.05$ (Tukey HSD test)

affected sapling survival (Table 3). Tukey HSD tests revealed that sapling survival was significantly higher inside the shrub canopy at low grazing pressure (Fig. 1b). Both of the broadleaved species, F. sylvatica and $A$. pseudoplatanus, showed a significantly higher sapling survival than the conifers $A$. alba and $P$. abies (Fig. 2b), even though sapling browsing was not different between species (Fig. 2a).

\section{Relative facilitation}

High grazing pressure reduced the relative facilitation of sapling browsing and sapling survival (Table 4). In addition, there were no significant effects of species and the interaction of grazing pressure by species on the relative facilitation of sapling browsing and sapling survival.

The relative facilitation model (Fig. 3) shows a hump-shaped curve for both sapling browsing and sapling survival. In the absence of cattle (exclosures), the 
Table 3 Results of ANOVA on effects of site, grazing pressure, position, species and their interactions on tree sapling browsing and survival

\begin{tabular}{|c|c|c|c|c|c|}
\hline \multirow[t]{2}{*}{ Source } & \multirow[t]{2}{*}{$d f$} & \multicolumn{2}{|c|}{ Browsing } & \multicolumn{2}{|c|}{ Survival } \\
\hline & & MS & $F$ & MS & $F$ \\
\hline Site & 2 & 0.002 & 0.173 & 0.018 & 1.966 \\
\hline $\begin{array}{l}\text { Grazing pressure } \\
\text { (GRAZ) }\end{array}$ & 1 & 0.227 & $24.299 * * *$ & 0.041 & $4.494 *$ \\
\hline Position (POS) & 1 & 0.992 & $106.233 * * *$ & 0.163 & $17.975^{* * *}$ \\
\hline Species (SPEC) & 3 & 0.001 & 0.104 & 0.255 & $28.017 * * *$ \\
\hline $\mathrm{GRAZ} \times \mathrm{POS}$ & 1 & 0.163 & $17.493 * * *$ & 0.083 & $9.171 * *$ \\
\hline $\mathrm{POS} \times \mathrm{SPEC}$ & 3 & 0.024 & 2.566 & 0.016 & 1.727 \\
\hline GRAZ $\times$ SPEC & 3 & 0.013 & 1.406 & 0.007 & 0.810 \\
\hline $\begin{array}{l}\mathrm{GRAZ} \times \mathrm{POS} \\
\times \mathrm{SPEC}\end{array}$ & 3 & 0.002 & 0.241 & 0.016 & 1.758 \\
\hline Error & 30 & 0.009 & & 0.009 & \\
\hline
\end{tabular}

$* P<0.05, * * P<0.01, * * * P<0.001$
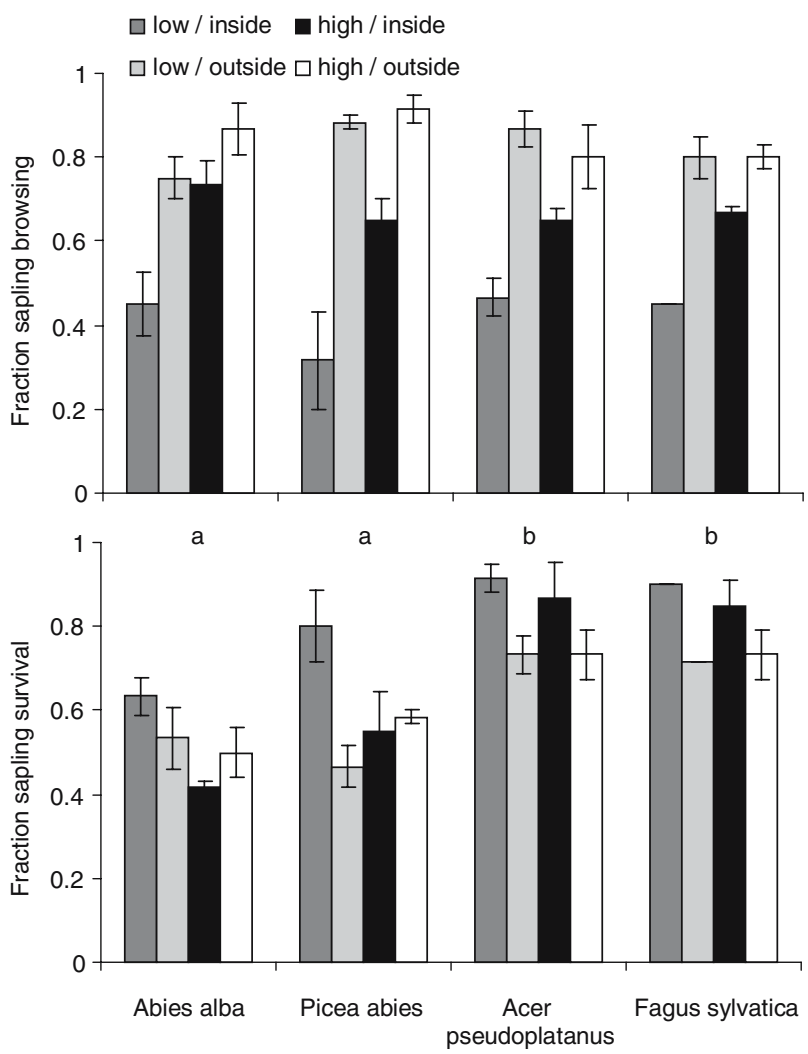

Fig. 2 Mean $( \pm 1 \mathrm{SE})$ fraction of saplings browsed and sapling survival per tree species at low and high grazing pressure inside and outside of the shrub canopy (averaged over site, $n=3$ ). Different letters indicate significant differences between species at $P<0.05$ (Tukey HSD test)

relative facilitation was close to zero. Relative facilitation was the highest at the low-grazing pressure treatment, decreasing at the high-grazing pressure treatment. The peaks were different for sapling browsing and sapling survival, with the former being higher.

\section{Discussion}

Sapling browsing and survival

Our study shows that, after one grazing season, the thorny shrub Rosa rubiginosa effectively protected tree saplings against browsing cattle and increased sapling survival. This clearly demonstrates associational resistance, i.e. reduced herbivory by association with a defended neighbour (Smit et al. 2006). We also found that grazing pressure exerted a great effect on this facilitative process. At the low-grazing pressure treatment, the $R$. rubiginosa shrubs protected the tree saplings, thereby increasing their survival and decreasing sapling browsing. At the high-grazing pressure treatment, the nurse shrubs did not increase sapling survival, and although the shrubs did protect the saplings from cattle browsing, their effects were less strong than at the low-grazing pressure treatment. As the nurse shrubs were also significantly more damaged under high grazing pressure, it would appear that they had lost their protective role - at least in part for the tree saplings. The selectivity of the cattle apparently decreased with increased grazing pressure; as the relative availability of the preferred species decreased, this led to the consumption of the less preferred species, as proposed by Crawley (1983).

At both grazing pressures sapling browsing was higher outside the canopy of the shrubs. However, sapling survival was only lower outside shrubs at the low-grazing pressure treatment; at the high-grazing pressure treatment, sapling survival did not differ among saplings inside and outside the shrub canopy (Fig. 1). Consequently, increased sapling browsing at the high grazing pressure did not lead to the expected increase in sapling mortality. Hall et al. (1992) similarly found increased damage - but no increased mortality among blue oak saplings (Quercus douglasii) at increased cattle grazing.

We found no difference in sapling browsing between the four tree species (Fig. 2a), indicating that cattle did not clearly distinguish between species, possibly because browsing of small saplings occurs by chance together with preferred focal species (Smit et al. 2006). It is also possible that differences in sapling browsing between species only appear when saplings are larger and therefore more visible to the cattle. This may explain why Liss (1988) did find differences in browsing damage between saplings of the four tree species during one grazing season (notably higher damage to A. pseudoplatanus and Fagus sylvatica).

Sapling survival was significantly higher for the deciduous broadleaved species ( $F$. sylvatica and A. pseudoplatanus) than for the evergreen coniferous 
Table 4 Results of ANOVA on the effects of site, grazing pressure, species and the interaction of grazing pressure ${ }^{\mathrm{a}}$ and species on the relative facilitation of sapling browsing and sapling survival

\begin{tabular}{|c|c|c|c|c|c|}
\hline \multirow[t]{2}{*}{ Source } & \multirow[t]{2}{*}{$d f$} & \multicolumn{2}{|c|}{ Relative facilitation of sapling browsing } & \multicolumn{2}{|c|}{ Relative facilitation of sapling survival } \\
\hline & & MS & $F$ & MS & $F$ \\
\hline SITE & 2 & 0.012 & 0.509 & 0.004 & 0.162 \\
\hline $\begin{array}{l}\text { Grazing pressure } \\
\text { (GRAZ) }\end{array}$ & 1 & 0.297 & $12.586 * * *$ & 0.139 & $5.078^{*}$ \\
\hline Species (SPEC) & 3 & 0.015 & 0.626 & 0.042 & 1.525 \\
\hline GRAZ × SPEC & 3 & 0.017 & 0.701 & 0.011 & 0.391 \\
\hline Error & 20 & 0.024 & & 0.027 & \\
\hline
\end{tabular}

$* P<0.05, * * P<0.01, * * * P<0.001$

${ }^{a}$ Difference in sapling browsing and sapling survival between saplings growninside and outside of the nurse shrub canopy

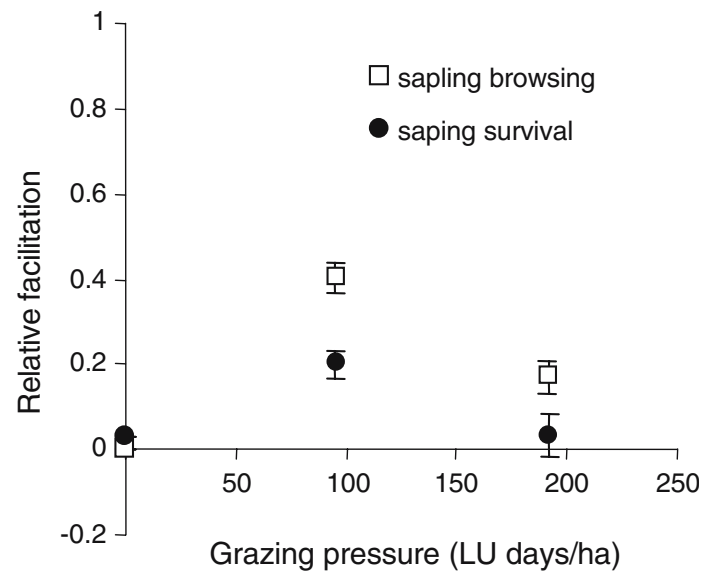

Fig. 3 Relative facilitation of sapling browsing and sapling survival (mean $\pm 1 \mathrm{SE}, n=3$ ) with increasing grazing pressure, expressed in number of livestock units (LU)-grazing days per hectare (1 livestock unit $=600 \mathrm{~kg})$

species (A. alba and P. abies) (Fig. 2b), despite equal browsing intensity. These findings are in accordance with the carbon/nutrient balance theory, which predicts that evergreen trees, which have a high carbon/nutrient ratio in their needles, suffer a more substantial loss of energy reserves when being defoliated than deciduous species, which store more carbon in their woody tissues (Hester et al. 2004; Krause and Raffa 1996). Deciduous broadleaved species are thought to be able to remobilise these stored energy reserves quickly for refoliation. As sapling survival after one grazing season was relatively high (on average 68\%), longer monitoring is required to verify if the observed differences in sapling survival between grazing treatments, positions and species remain over a longer period.

\section{Relative facilitation}

In contrast with current conceptual facilitation models that predict an increase in facilitation with increasing abiotic stress (Bertness and Callaway 1994; Callaway et al. 2002; Callaway and Walker 1997; Holmgren et al. 1997), we found a decrease in relative facilitation (expressed in terms of sapling browsing and sapling survival) with increased biotic stress (grazing pressure): the relationship shows a hump-shaped curve (Fig. 3). We propose that the nurse species, which in this case was the thorny shrub $R$. rubiginosa, lost its protective effects for the nearby-planted tree saplings due to increased grazing pressure at the high-grazing pressure treatment: the intense grazing caused severe damage to the nurse shrubs, resulting in higher sapling browsing and lower sapling survival inside the shrub canopy than was found at the low-grazing pressure treatment.

We acknowledge that our results are based upon a specific set of species with merely three different grazing pressures in one particular ecosystem. However, we believe that our findings are relevant for other nurse plant-protégé relationships and can be extrapolated to different species and environmental characteristics. In Fig. 4 we present a conceptual model of relative facilitation along a gradient of biotic stress. We argue how herbivore resistance of protégé species, unpalatability of nurse species and the productivity of a site would alter a basic model of a facilitative relationship between a nurse plant and an associated protégé (line 1, Fig. 4).

Our data show that relative facilitation was higher for sapling browsing than for sapling survival (Fig. 3). Sapling survival, but not sapling browsing, varied between species, being higher for the broadleaved deciduous than for evergreen coniferous species, indicating the higher herbivore resistance of the former. The survival of an extremely herbivore-resistant protégé species would be essentially independent of the presence of a nurse shrub as it is not likely to die as a result of frequent browsing. Hence, the peak of the relative facilitation curve (for protégé survival) would 


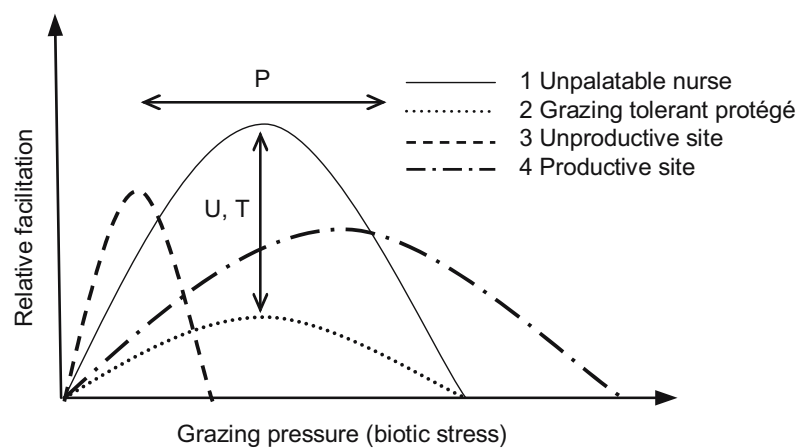

Fig. 4 Conceptual model of relative facilitation and grazing pressure (biotic stress). Peaks shift horizontally with site productivity $(P)$ and vertically with the unpalatability of nurse plants $(U)$ or grazing tolerance of the associated protégés $(T)$

shift downwards with increased herbivore resistance of the protégé species (line 2, Fig. 4). In the same manner, the peak shifts upwards with decreasing herbivore resistance of the protégé species. However, we found no significant effects of species on the relative facilitation of sapling survival (Table 4), possibly because it would be very difficult to detect sapling mortality after only one grazing season, as damaged saplings may still die during the following winter.

The unpalatability of the nurse plants also affects the likelihood of associated recruits being browsed and, consequently, affects the shape of the relative facilitation model. An extremely toxic and well-defended nurse plant would give "optimal" protection to associated recruits. As such, the peak of the relative facilitation curve shifts up with increased unpalatability of the nurse species (lines 1 and 2, Fig. 4).

Food availability determines the carrying capacity of a site for vertebrates (Crawley 1983); in other words, highly productive grasslands generally support higher cattle loads than less productive grasslands. Consequently, at equivalent cattle loads, unpalatable plants are expected to be browsed upon earlier in the less productive grasslands than in the highly productive ones, resulting in earlier damage to the associated protégés. Therefore, the peak of the relative facilitation curve is expected to shift to the left (at lower grazing pressure) at the less productive sites (line 3, Fig. 4) and to the right at the more highly productive sites (line 4, Fig. 4).

We expect similar patterns to occur in the relative facilitation between plants along comparable biotic environmental gradients in a wide range of ecosystems. The study of Hamback et al. (2000) provides an example of associational resistance in shore vegetations in Sweden: in the presence of the shrub Myrica gale damage to Lytrhum salicaria, caused by the specialist chrysomelid beetle Galerucella calmariensis, was reduced, as the former reduces the beetles' ability to locate its host L. salicaria. We expect that the facilitative effects of the nurse shrub $M$. gale for $L$. salicaria will decrease when the abundance of the beetles increases (biotic stress factor) because then a relatively higher number of beetles will be able to reach and damage the associated L. salicaria.

Our study demonstrates that the relationship between facilitation and biotic stress (disturbance sensu Grime 1977) follows a hump-shaped curve: facilitation decreases at high levels of biotic stress. These results are in contrast with current models that predict increased facilitation with abiotic stress (stress sensu Grime 1977). It would be of interest to determine whether our observed pattern also applies to abiotic stress gradients; i.e. decreasing facilitation at high levels of abiotic stress (e.g. drought, salinity). If so, current conceptual facilitation models will need to be revisited. Empirical studies are now needed to verify the applicability of our model.

Acknowledgements We are grateful to the agronomic research station of Agroscope Changins (RAC) for allowing us to use la Petite Ronde as field site and for helping us set up the exclosures. Further, we thank C. Rosat for his help with transplanting the shrubs and trees, F. Freléchoux and R. Smit for their help and advice during this study and $\mathrm{M}$. Pohl for her extensive help with gathering the data. We thank M. Holmgren for improving this manuscript with useful comments. This project was funded by the National Centre of Competence in Research (NCCR) Plant Survival of the Swiss National Science Foundation.

\section{References}

Atstatt PR, Odowd DJ (1976) Plant defense guilds. Science 193:24-29

Bakker ES, Olff H, Vandenberghe C, De Maeyer K, Smit R, Gleichman JM, Vera FWM (2004) Ecological anachronisms in the recruitment of temperate light-demanding tree species in wooded pastures. J Appl Ecol 41:571-582

Bergman M, Iason GR, Hester AJ (2005) Feeding patterns by roe deer and rabbits on pine, willow and birch in relation to spatial arrangement. Oikos 109:513-520

Bertness MD, Callaway R (1994) Positive interactions in communities. Trends Ecol Evol 9:191-193

Bertness MD, Ewanchuk PJ (2002) Latitudinal and climate-driven variation in the strength and nature of biological interactions in New England salt marshes. Oecologia 132:392-401

Bokdam J (2003) Nature conservation and grazing management. Free ranging cattle as a driving force for cyclic vegetation succession. PUDOC, Wageningen University, Wageningen

Bruno JF, Stachowicz JJ, Bertness MD (2003) Inclusion of facilitation into ecological theory. Trends Ecol Evol 18:119-125

Callaway RM, Walker LR (1997) Competition and facilitation: a synthetic approach to interactions in plant communities. Ecology 78:1958-1965

Callaway RM, Brooker RW, Choler P, Kikvidze Z, Lortie CJ, Michalet R, Paolini L, Pugnaire FI, Newingham B, Aschehoug ET, Armas C, Kikodze D, Cook BJ (2002) Positive 
interactions among alpine plants increase with stress. Nature 417:844-848

Choler P, Michalet R, Callaway RM (2001) Facilitation and competition on gradients in alpine plant communities. Ecology 82:3295-3308

Crawley MJ (1983) Herbivory. Studies in ecology, vol. 10. The dynamics of animal-plant interactions. Blackwell, Oxford

Flores J, Jurado E (2003) Are nurse-protégé interactions more common among plants from arid environments? J Veg Sci 14:911-916

Franks SJ (2003) Facilitation in multiple life-history stages: evidence for nucleated succession in coastal dunes. Plant Ecol 168:1-11

Gomez-Aparicio L, Zamora R, Gomez JM, Hodar JA, Castro J, Baraza E (2004) Applying plant facilitation to forest restoration: a meta-analysis of the use of shrubs as nurse plants. Ecol Appl 14:1128-1138

Grime JP (1977) Evidence for existence of 3 primary strategies in plants and its relevance to ecological and evolutionary theory. Am Nat 111:169-1194

Hall LM, George MR, McCreary DD, Adams TE (1992) Effects of cattle grazing on blue oak seedling damage and survival. J Range Manage 45:503-506

Hambäck PA, Ågren J, Ericson L (2000) Associational resistance: insect damage to purple loosestrife reduced in thickets of sweet gale. Ecology 81:1784-1794

Hester AJ, Millard P, Baillie GJ, Wendler R (2004) How does timing of browsing affect above- and below-ground growth of Betula pendula, Pinus sylvestris and Sorbus aucuparia? Oikos 105:536-550

Holmgren M, Scheffer M, Huston MA (1997) The interplay of facilitation and competition in plant communities. Ecology 78:1966-1975
Kareiva PM, Bertness MD (1997) Re-examining the role of positive interactions in communities. Ecology 78:1945

Krause SC, Raffa KF (1996) Differential growth and recovery rates following defoliation in related deciduous and evergreen trees. Trees-Struct Funct 10:308-316

Liss BM (1988) Der Einfluss von weidevieh und wild auf die natürliche und künstliche Verjüngung im Bergmischwald der ostbayerischen Alpen. Forstwiss Cbl 107: 14-25

Maestre FT, Valladares F, Reynolds JF (2005) Is the change of plant-plant interactions with abiotic stress predictable? A meta-analysis of field results in arid environments. J Ecol 93:748-757

Milchunas DG, Noy-Meir I (2002) Grazing refuges, external avoidance of herbivory and plant diversity. Oikos 99:113-130

Rousset O, Lepart J (2000) Positive and negative interactions at different life stages of a colonizing species (Quercus humilis). J Ecol 88:401-412

Shumway SW (2000) Facilitative effects of a sand dune shrub on species growing beneath the shrub canopy. Oecologia 124:138-148

Smit C, Béguin D, Buttler A, Mueller-Schaerer H (2005) Safe sites for tree regeneration in wooded pastures: a case of associational resistance? J Veg Sci 16:209-214

Smit C, den Ouden J, Mueller-Schaerer H (2006) Unpalatable plants facilitate tree sapling survival in wooded pastures. J Appl Ecol 43:305-312

Tewksbury JJ, Lloyd JD (2001) Positive interactions under nurseplants: spatial scale, stress gradients and benefactor size. Oecologia 127:425-434

Tirado R, Pugnaire FI (2003) Shrub spatial aggregation and consequences for reproductive success. Oecologia 136:296-301 